\title{
Hydrogen Oxidation-Driven Hot Electron Flow Detected by Catalytic Nanodiodes
}

\author{
Antoine Hervier ${ }^{1}$, J. Russell Renzas ${ }^{1}$, Jeong Y.Park ${ }^{2},{ }^{*},{ }^{\dagger}$, and \\ Gabor A. Somorjai ${ }^{1,2, *}$ \\ ${ }^{I}$ Department of Chemistry, University of California, Berkeley, CA 94720 \\ ${ }^{2}$ Materials Sciences Division and Chemical Sciences Division, Lawrence Berkeley \\ National Laboratory, Berkeley, CA 94720
}

\begin{abstract}
Hydrogen oxidation on platinum is shown to be a surface catalytic chemical reaction that generates a steady state flux of hot $(>1 \mathrm{eV})$ conduction electrons. These hot electrons are detected as a steady-state chemicurrent across $\mathrm{Pt} / \mathrm{TiO}_{2}$ Schottky diodes whose Pt surface is exposed to hydrogen and oxygen. Kinetic studies establish that the chemicurrent is proportional to turnover frequency for temperatures ranging from $298 \mathrm{~K}$ to $373 \mathrm{~K}$, for $\mathrm{P}_{\mathrm{H} 2}$ between 1 and 8 Torr and $\mathrm{P}_{\mathrm{O} 2}$ at 760 Torr. Both chemicurrent and turnover frequency exhibit a first order dependence on $\mathrm{P}_{\mathrm{H} 2}$.
\end{abstract}

† Current address: Graduate school of EEWS (Energy, Environment, Water, and Sustainability), Korea Advanced Institute of Science and Technology (KAIST), Yuseong-gu, Daejeon, Republic of Korea.

* To whom correspondence should be addressed. E-mail: somorjai@berkeley.edu, jypark@lbl.gov. 
Any exothermic adsorption process or chemical reaction at a metal surface produces electron-hole pairs since no gap exists between occupied and unoccupied electronic energy levels in metals. Usually only a small fraction of the reaction heat is transferred to an electron-hole pair. A few chemical processes on high work-function metal surfaces have been recently discovered that transfer a substantial fraction of the reaction heat to the kinetic energy of individual metal electrons ${ }^{1-12}$. There is growing evidence which indicates that these energetic electrons, often called hot electrons, influence surface reactivity ${ }^{13,14}$. These energetic subsurface electrons have been directly detected in metal/semiconductor Schottky diodes whose metal surface is subject to a chemical process ${ }^{15,16,17}$. These diodes are made by depositing a thin-metal film onto a semiconductor in such a way that a Schottky barrier between the two is created, as shown in Fig. 1a. If the fraction of the reaction heat that is transferred to a metal electron exceeds the Schottky barrier, the electron will travel ballistically through the metal conduction band, and possibly reach the semiconductor, where it would contribute to the observed electric current, referred to as chemicurrent as shown in Fig. 1a. Non-catalytic metal-semiconductor diodes have been used to prove that hot electrons are generated in adsorption reactions in ultrahigh vacuum (UHV) at temperatures below $150 \mathrm{~K}^{18-20}$. By using catalytic metal-semiconductor diodes such as $\mathrm{Pt} / \mathrm{TiO}_{2}$ or $\mathrm{Pt} / \mathrm{GaN}$, it has also been possible to detect steady chemicurrent from catalytic $\mathrm{CO}$ oxidation at atmospheric pressure, between $400 \mathrm{~K}_{\text {and }} 550 \mathrm{~K}^{16,21}$. A family of models assuming that the nonadiabatic energy transfer during a surface chemical process is dominated by electron-hole pair excitations has been suggested. 4, 22, 23, 24 . Nonetheless, the question of whether surface catalytic reactions other than $\mathrm{CO}$ oxidation can generate chemicurrent has not 
been confirmed. This question is of importance because it can indicate that hot electron generation during an exothermic catalytic reaction is a general phenomenon.

This report describes the detection of steady state chemicurrent in catalytic hydrogen oxidation on Pt. Hydrogen oxidation has a reaction heat of $\Delta h_{\mathrm{H}_{2} \mathrm{O}}=-2.5 \mathrm{eV}$ per water molecule ${ }^{25}$, which is well below platinum's work function of 5-6 eV, and below the thresholds for Pt surface or bulk electronic collective modes ${ }^{11}$. Distinct reaction pathways may be followed in different conditions ${ }^{25-28}$. Hydrogen oxidation well above water desorption temperature proceeds mainly via a Langmuir-Hinshelwood rate-limiting step $\mathrm{O}_{(a)}+\mathrm{H}_{(\mathrm{a})} \rightarrow \mathrm{OH}_{(\mathrm{a})}{ }^{27,29}$. The reactive desorption of $\mathrm{H}_{2} \mathrm{O}$ may involve $\mathrm{H}_{(\mathrm{a})}+\mathrm{OH}_{(\mathrm{a})} \rightarrow \mathrm{H}_{2} \mathrm{O}_{(\mathrm{g})} \quad 28,26$ or $2 \mathrm{OH}_{(\mathrm{a})} \rightarrow \mathrm{H}_{2} \mathrm{O}_{(\mathrm{g})}+\mathrm{O}_{(\mathrm{a})}$; with reported low coverage activation energies of $16 \mathrm{kcal} / \mathrm{mol}$ and $18 \mathrm{kcal} / \mathrm{mol}$ respectively ${ }^{30}$. The activation energy is substantially lowered below the water desorption temperature, as surface water catalyzes hydroxyl formation ${ }^{28}$. On oxygen-covered $\mathrm{Pt}(111)$, another channel, $\mathrm{H}_{2} \mathrm{O}_{(\mathrm{g})}+\mathrm{O}_{(\mathrm{a})} \rightarrow 2 \mathrm{OH}_{(\mathrm{a})}$, is open above $150 \mathrm{~K}$, and reactive desorption, $2 \mathrm{OH}_{(\mathrm{a})} \rightarrow \mathrm{H}_{2} \mathrm{O}_{(\mathrm{g})}+\mathrm{O}_{(\mathrm{a})}$ begins above $215 \mathrm{~K}$ and continues beyond $300 \mathrm{~K} .{ }^{31}$ Most of these studies are conducted in UHV; much less is known at atmospheric pressure.

In this paper, we present the experimental detection of a continuous flux of energetic (hot) electrons during catalytic hydrogen oxidation using $\mathrm{Pt} / \mathrm{TiO}_{2}$ catalytic nanodiodes at atmospheric pressures. The hydrogen oxidation reaction reported to produce hot electrons is the second catalytic reaction under atmospheric pressures following the $\mathrm{CO}$ oxidation reaction that was reported elsewhere earlier ${ }^{15,21}$. We establish the dependence of the hot electron flow, referred to as chemicurrent, and reaction turnover rate on hydrogen partial pressure. 
The design of nanodiodes tested in this work is described elsewhere ${ }^{32}$. Briefly, ptype (100) silicon wafers with a $500 \mathrm{~nm}$ thermally grown silicon oxide film were subjected to a standard piranha clean prior to further processing. The first step consists of depositing a $4 \times 4 \mathrm{~mm}^{2}, 150 \mathrm{~nm}$ thick film of titanium oxide onto the silicon oxide through an aluminum shadow mask, by reactive direct current (DC) magnetron sputtering. The wafer is then annealed in $\mathrm{O}_{2}$, using rapid thermal annealing at $375{ }^{\circ} \mathrm{C}$ for 5 minutes. A $10 \mathrm{~nm}$ film of titanium is then deposited through a second mask using electron beam evaporation. A $50 \mathrm{~nm}$ gold film, which constitutes the nanodiode's two ohmic electrodes, is then deposited through the same mask. The titanium serves as an adhesive between the gold and the titanium oxide. Finally, a $5 \mathrm{~nm}$ platinum catalyst film is deposited through a third mask, for a total active area of $3 \mathrm{~mm}^{2}$ per diode. Barrier heights and ideality factors for the nanodiode are obtained by fitting the current-voltage $(\mathrm{I}-\mathrm{V})$ curves of diodes to the thermionic emission equation ${ }^{32}$. Typical barrier height and ideality factors for the $\mathrm{Pt} / \mathrm{TiO}_{2}$ nanodiodes are $1.1-1.2 \mathrm{eV}$, and 1.5-2.0, respectively.

The nanodiode is placed on a ceramic heater, and the temperature is monitored by a thermocouple, fluctuating by less than $0.5 \mathrm{~K}$. The turnover of water molecules was obtained by monitoring the amount of $\mathrm{H}_{2}$ during the reaction, using a gas chromatograph connected to the chamber by a sample loop equipped with a circulation pump. The nanodiode's electrodes are connected to an electrical circuit with gold wires, making it possible to characterize the device by measuring its I-V curve with a sourcemeter. The same sourcemeter is used to measure chemicurrent passing through the diode while the chemical reaction is taking place. No voltage bias is applied to the diode. 
Since $\mathrm{TiO}_{2}$ is quickly (within seconds) reduced by atomic hydrogen, which diffuses through the platinum film ${ }^{33}$, and since the hydrogen/oxygen mixture is explosive in certain conditions, oxygen is used in large excess (>99\%). The reaction is conducted in a batch reactor with a volume of about 1 liter, pumped down to $10^{-6}$ Torr in between runs. The rectifying performance of the diodes degrades with hydrogen exposure because of the spill-over effect as shown in Figure 1Sa of the supporting information. Under our hydrogen oxidation conditions, however, where we have a large excess of oxygen, the diodes sustain their rectifying behavior (See Figure $1 \mathrm{Sb}$ of the supporting information). This suggests that the oxygen keeps the semi-conductor part of the diode oxidized, or prevents the hydrogen from diffusing through the platinum. With spill-over largely absent, the Schottky barrier remains constant on the time scale of the experiments.

Fig. $1 \mathrm{~b}$ shows the current measured with a $\mathrm{Pt} / \mathrm{TiO}_{2}$ diode under reaction conditions, as a function of time, during a temperature ramp from $298 \mathrm{~K}$ to $373 \mathrm{~K}$, in 6 Torr of $\mathrm{H}_{2}$ and 760 Torr of $\mathrm{O}_{2}$. The current increases with temperature and is stable at fixed temperatures. The thermoelectric current was separately measured under 1 atmosphere of $\mathrm{He}$, and is found to be lower than $0.3 \mathrm{nA}$ at $373 \mathrm{~K}$. Because the current detected under hydrogen oxidation at $373 \mathrm{~K}(17 \pm 1 \mathrm{nA})$ is much higher than the thermoelectric current, most of the current signal can be attributed to the chemicurrent. The reaction is concurrently monitored using a gas chromatograph in order to determine chemicurrent yield (number of electrons detected per reaction event). Fig. 1c shows the number of water molecules per platinum site produced on the $\mathrm{Pt} / \mathrm{TiO}_{2}$ diode under 6 Torr of $\mathrm{H}_{2}$ and 760 Torr of $\mathrm{O}_{2}$, as a function of time; it is assumed that the surface Pt site density is equivalent to that of $\operatorname{Pt}(111)$. The turnover frequency at different temperatures 
is obtained by taking the slope of the plots, and increases with temperature, as shown in Fig. 1c.

The activation energy is determined using the turnover rate and chemicurrent measured as a function of temperature. Fig. 2 shows the resulting Arrhenius plots on the same graph. The error bars in the plot correspond to the standard deviations of the measurements. The two resulting activation energies match $(7.4 \pm 0.3 \mathrm{kcal} / \mathrm{mol}$ for chemicurrent and $7.6 \pm 0.6 \mathrm{kcal} / \mathrm{mol}$ for turnover rate), which implies that the chemicurrent originates from the catalytic reaction. Again, thermoelectric current is negligible $(<0.3 \mathrm{nA})$ in the range of temperatures $(298-373 \mathrm{~K})$ used here. The effect of an increase in the sample temperature due to the heat of reaction has been shown to be negligible in previous work ${ }^{21}$. The activation energy for hydrogen oxidation under identical conditions (6 Torr of $\mathrm{H}_{2}$ and 760 Torr of $\mathrm{O}_{2}$ ) measured on a Pt foil separately is $8.3( \pm 0.6) \mathrm{kcal} / \mathrm{mol}$, which is comparable to that on $\mathrm{Pt} / \mathrm{TiO}_{2}$ nanodiodes within the experimental error.

The dependence of chemicurrent and turnover rate on the partial pressure of $\mathrm{H}_{2}$ is also investigated. Fig. 3a shows the measurement of turnover rate at five different partial pressures of $\mathrm{H}_{2}$ from 1 to 8 Torr, and indicates a linear relationship between water formation and $\mathrm{H}_{2}$ partial pressure, consistent with a Langmuir-Hinshelwood mechanism. Fig. $3 b$ shows the plot of chemicurrent as a function of partial pressure of $\mathrm{H}_{2}$ measured at four different temperatures, with again a linear dependence between chemicurrent and partial pressure of $\mathrm{H}_{2}$.

The apparent chemicurrent yield can be obtained by dividing chemicurrent (number of electron per second) by turnover rate (number of product molecules per 
platinum site per second). Therefore, the chemicurrent yield represents the hot electrons collected per product molecule formed on a single metal site. Its value in hydrogen oxidation, based on measurements at several different temperatures, is $(1.1 \pm 0.1) \times 10^{-4}$. The apparent yield in $\mathrm{CO}$ oxidation on the same $5 \mathrm{~nm} \mathrm{Pt} / \mathrm{TiO}_{2}$ diode $^{32}$ is $2.3 \pm 0.5 \times 10^{-4}$. The lower chemicurrent yield of $\mathrm{H}_{2}$ oxidation compared to $\mathrm{CO}$ oxidation may be associated with the lower reaction heat of $\mathrm{H}_{2}$ oxidation $(2.5 \mathrm{eV}$ per product molecule, $\mathrm{H}_{2} \mathrm{O}^{34,35}$ ) compared to that of $\mathrm{CO}$ oxidation (2.9 eV per product molecule, $\mathrm{CO}_{2}{ }^{36}$ ). These apparent chemicurrent yields are comparable in order of magnitude to those seen in chemisorption of hydrogen on $\mathrm{Ag} / \mathrm{n}-\mathrm{Si}(111)$ and $\mathrm{Cu} / \mathrm{n}-\mathrm{Si}(111)$ diodes with $7.5 \mathrm{~nm}$ metal films (chemicurrent yields of $4.5 \times 10^{-3}$ and $1.5 \times 10^{-4}$ electrons per adsorption event, respectively) ${ }^{20}$.

These $\mathrm{H}_{2}$ oxidation results, together with earlier results for $\mathrm{CO}$ oxidation, can be seen as model reactions for hot electron generation in the complete combustion of hydrogen and oxygen containing species: hydrocarbons, alcohols, ethers, aldehydes, ketones, and carboxylic acids, etc. This points to potential applications of nanodiodes as chemical sensors that could perform across a wide pressure range from the ultrahigh vacuum to the high pressures relevant in industrial catalysis.

In conclusion, the catalytic oxidation of hydrogen on a $\mathrm{Pt} / \mathrm{TiO}_{2}$ nanodiode yields a steady state chemicurrent, which is proportional to turnover frequency. In contrast to the earlier studies of $\mathrm{CO}$ oxidation, stronger evidence for the intimate correlation between the surface chemistry and hot electron flow is presented here as the thermoelectric effect is negligible due to the low temperature of reaction (below $120{ }^{\circ} \mathrm{C}$ ) compared to the earlier studies of $\mathrm{CO}$ oxidation. The fact that both $\mathrm{H}_{2} / \mathrm{O}_{2}$ and $\mathrm{CO}$ oxidation are exothermic 
catalytic reactions yielding experimentally measured hot electron flow suggests that the chemical phenomenon of hot electron production during catalytic reactions on transition metal surfaces may be widespread.

\section{Acknowledgments}

The authors acknowledge Martin Head-Gordon and Sergey Maximoff for insightful comments. This work has been supported by the Director, Office of Science, Office of Basic Energy Sciences, Division of Chemical Sciences, Geological and Biosciences and Division of Materials Sciences and Engineering of the U.S. Department of Energy under contract No. DE-AC02-05CH11231. 


\section{References}

1. Denzler, D. N.; Frischkorn, C.; Hess, C.; Wolf, M.; Ertl, G. Physical Review Letters 2003, 91, (22), 226102-1-226102-4.

2. Gadzuk, J. W. Journal of Physical Chemistry B 2002, 106, (33), 8265-8270.

3. Masel, R. I., Principles of Adsorption and Reaction on Solid Surfaces. Wiley: New York, 1996.

4. Mizielinski, M. S.; Bird, D. M.; Persson, M.; Holloway, S. Journal of Chemical Physics 2005, 122, (8), 084710.

5. $\quad$ Somorjai, G. A.; Park, J. Y. Catalysis Letters 2007, 115, (3-4), 87-98.

6. Hasselbrink, E. Current Opinion in Solid State \& Materials Science 2006, 10, (34), 192-204.

7. Wodtke, A. M.; Matsiev, D.; Auerbach, D. J. Progress in Surface Science 2008, 83, (3), 167-214.

8. $\quad$ Huang, Y.; Wodtke, A. M.; Hou, H.; Rettner, C. T.; Auerbach, D. J. Physical Review Letters 2000, 84, (13), 2985-2988.

9. Kasemo, B.; Tornqvist, E.; Norskov, J. K.; Lundqvist, B. I. Surface Science 1979, $89,(1-3), 554-565$.

10. Nienhaus, H. Surface Science Reports 2002, 45, (1-2), 3-78.

11. Liebsch, A. Electronic excitations at metal surfaces (Plenum Press, New York, 1997).

12. Shenvi, N.; Cheng, H. Z.; Tully, J. C. Physical Review A 2006, 74, (6), 10.

13. Komeda, T.; Kim, Y.; Fujita, Y.; Sainoo, Y.; Kawai, M. Journal of Chemical Physics 2004, 120, (11), 5347-5352.

14. Maksymovych, P.; Sorescu, D. C.; Jordan, K. D.; Yates, J. T. Science 2008, 322, (5908), 1664-1667.

15. Ji, X. Z.; Zuppero, A.; Gidwani, J. M.; Somorjai, G. A. Nano Letters 2005, 5, (4), 753-756.

16. Park, J. Y.; Somorjai, G. A. Journal of Vacuum Science and Technology B 2006, 24, (4), 1967-1971.

17. Park, J. Y.; Lee, H.; Renzas, J. R.; Zhang, Y. W.; Somorjai, G. A. Nano Letters 2008, 8, (8), 2388-2392.

18. Gergen, B.; Weyers, S. J.; Nienhaus, H.; Weinberg, W. H.; McFarland, E. W. Surface Science 2001, 488, (1-2), 123-132.

19. Krix, D.; Nünthel, R.; Nienhaus, H. Journal of Vacuum Science and Technology A 2006, 25, (4), 1156-1160.

20. Nienhaus, H.; Bergh, H. S.; Gergen, B.; Majumdar, A.; Weinberg, W. H.; McFarland, E. W. Physical Review Letters 1999, 82, (2), 446-449.

21. Park, J. Y.; Somorjai, G. A. Chemphyschem 2006, 7, (7), 1409-1413.

22. Maximoff, S. N.; Head-Gordon, M. P. Proceedings of the National Academy of Sciences of the United States of America 2009, 106, (28), 11460-11465.

23. Persson, M.; Hellsing, B. Physical Review Letters 1982, 49, (9), 662-665.

24. Trail, J. R.; Graham, M. C.; Bird, D. M.; Persson, M.; Holloway, S. Physical Review Letters 2002, 88, (16), 4. 
25. Williams, W. R.; Marks, C. M.; Schmidt, L. D. Journal of Physical Chemistry 1992, 96, (14), 5922-5931.

26. Michaelides, A.; Hu, P. Journal of the American Chemical Society 2001, 123, (18), 4235-4242.

27. Smith, J. N.; Palmer, R. L. Journal of Chemical Physics 1972, 56, (1), 13-\&.

28. Volkening, S.; Bedurftig, K.; Jacobi, K.; Wintterlin, J.; Ertl, G. Physical Review Letters 1999, 83, (13), 2672-2675.

29. Verheij, L. K.; Hugenschmidt, M. B.; Colln, L.; Poelsema, B.; Comsa, G.

Chemical Physics Letters 1990, 166, (5-6), 523-530.

30. Anton, A. B.; Cadogan, D. C. Surface Science 1990, 239, (3), L548-L560.

31. Fisher, G. B.; Sexton, B. A. Physical Review Letters 1980, 44, (10), 683-686.

32. Park, J. Y.; Renzas, J. R.; Hsu, B. B.; Somorjai, G. A. Journal of Physical

Chemistry C 2007, 111, (42), 15331-15336.

33. Roland, U.; Braunschweig, T.; Roessner, F. Journal of Molecular Catalysis A 1997, 127, (1-3), 61-84.

34. Hanson, F. V.; Boudart, M. Journal of Catalysis 1978, 53, (1), 56-67.

35. Hellsing, B.; Kasemo, B.; Zhdanov, V. P. Journal of Catalysis 1991, 132, (1), $210-228$

36. Kwong, D. W. J.; Deleon, N.; Haller, G. L. Chemical Physics Letters 1988, 144, (5-6), 533-540. 


\section{Figure Captions}

Figure 1. : (a) The inset shows the energy diagram of a catalytic metal-semiconductor diode, along with a cross-section of the $\mathrm{Pt} / \mathrm{TiO}_{2}$ diode. The metal-semiconductor interface creates a Schottky barrier $\left(\mathrm{E}_{\mathrm{SB}}\right)$, equal to the difference between the metal's work function and the semiconductor's electron affinity. In order to be collected, electrons need to have an excess energy higher than the Schottky barrier. (b) Chemicurrent measured at different temperatures on a $\mathrm{Pt} / \mathrm{TiO}_{2}$ diode, in 6 Torr of $\mathrm{H}_{2}$ and 760 Torr $\mathrm{O}_{2}$. (c) Plot of water molecules produced in hydrogen oxidation reaction per platinum site as a function time. Turnover at different temperatures can be obtained by taking the slope of the plots.

Figure 2. Arrhenius plots obtained from chemicurrent and turnover measurements on a $\mathrm{Pt} / \mathrm{TiO}_{2}$ diode with pressure of 6 Torr of $\mathrm{H}_{2}$ and 760 Torr $\mathrm{O}_{2}$. Both give similar activation energies, which implies that hot electron generation under hydrogen oxidation is proportional to the catalytic turnover rate. The error is associated with multiple measurements of chemicurrent and turnover rates.

Figure 3. (a) Turnover frequency for different pressures of $\mathrm{H}_{2}$ in 760 Torr of $\mathrm{O}_{2}$, at $353 \mathrm{~K}$, measured with gas chromatography. (b) A plot of chemicurrent as a function of different pressures of $\mathrm{H}_{2}$ in 760 Torr of $\mathrm{O}_{2}$. Both series of measurements exhibit a linear increase as the pressure of hydrogen rises. 

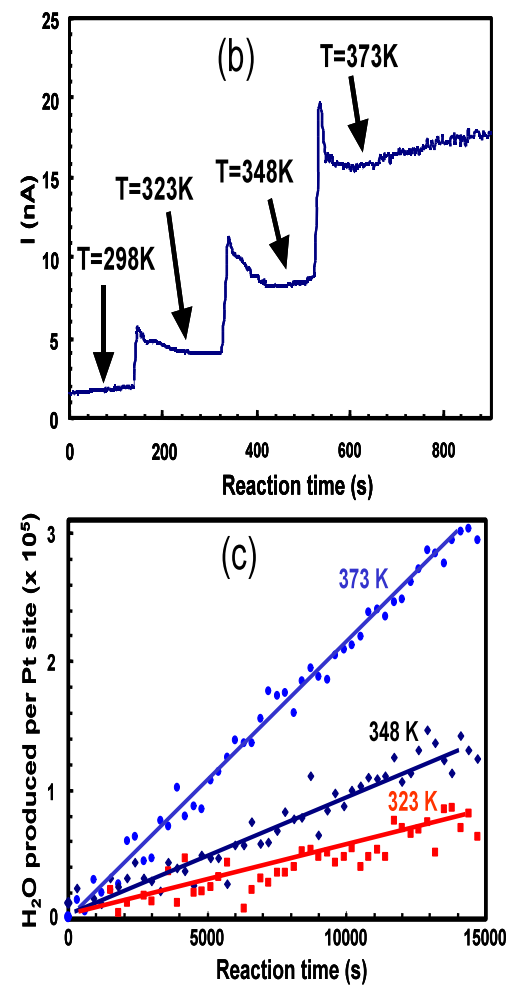

Figure 1 


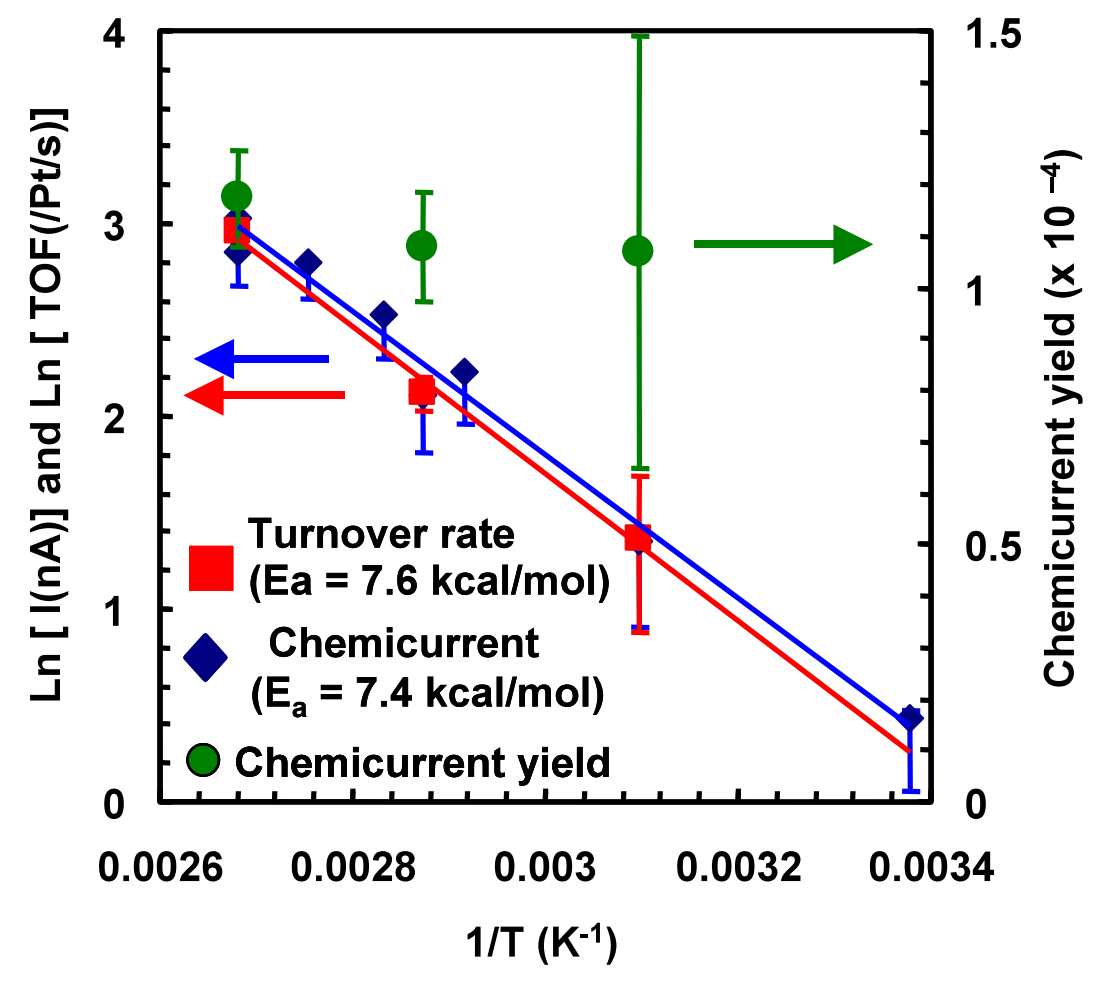

Figure 2 


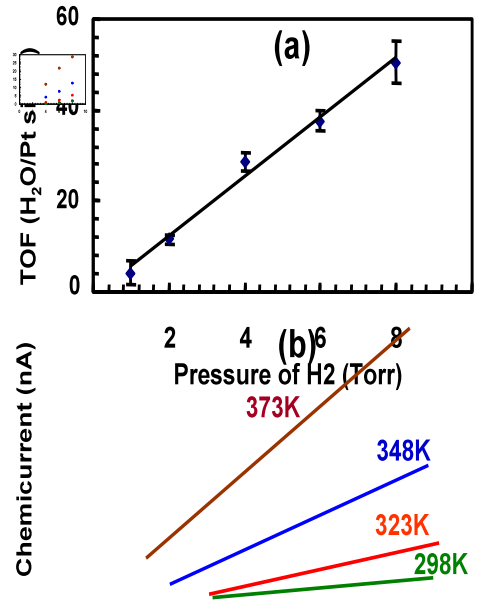

Pressure of hydrogen (Torr)

Figure 3 


\section{LEGAL DISCLAIMER}

This document was prepared as an account of work sponsored by the United States Government. While this document is believed to contain correct information, neither the United States Government nor any agency thereof, nor The Regents of the University of California, nor any of their employees, makes any warranty, express or implied, or assumes any legal responsibility for the accuracy, completeness, or usefulness of any information, apparatus, product, or process disclosed, or represents that its use would not infringe privately owned rights. Reference herein to any specific commercial product, process, or service by its trade name, trademark, manufacturer, or otherwise, does not necessarily constitute or imply its endorsement, recommendation, or favoring by the United States Government or any agency thereof, or The Regents of the University of California. The views and opinions of authors expressed herein do not necessarily state or reflect those of the United States Government or any agency thereof or The Regents of the University of California. 